\title{
Head injury mechanisms in FIS World Cup alpine and freestyle skiers and snowboarders
}

\author{
Sophie Elspeth Steenstrup, ${ }^{1}$ Arnhild Bakken, ${ }^{1}$ Tone Bere, ${ }^{2}$ Declan Alexander Patton, ${ }^{1,3}$ \\ Roald Bahr ${ }^{1}$
}

- Additional material is published online only. To view please visit the journal online (http://dx.doi.org/10.1136/ bjsports-2017-098240).

${ }^{1}$ Oslo Sports Trauma Research Center, Department of Sports Medicine, Norwegian School of Sport Sciences, Oslo, Norway ${ }^{2}$ Orthopaedic Department, Oslo University Hospital Ullevaal,

Oslo, Norway

${ }^{3}$ Australian Collaboration for Research into Injury in Sport and its Prevention (ACRISP), Federation University Australia, Ballarat, Victoria, Australia

\section{Correspondence to}

Sophie Elspeth Steenstrup, Oslo Sports Trauma Research Center, Department of Sports Medicine, Norwegian School of Sport Sciences, 0863 Oslo, Norway; s.e.steenstrup@nih.no

Accepted 30 October 2017 Published Online First 13 November 2017
CrossMark

To cite: Steenstrup SE, Bakken A, Bere T, et al. Br J Sports Med 2018;52:61-69.

\section{ABSTRACT}

Introduction Head injuries represent a concern in skiing and snowboarding, with traumatic brain injuries being the most common cause of death.

Aim To describe the mechanisms of head and face injuries among World Cup alpine and freestyle skiers and snowboarders.

Methods We performed a qualitative analysis of videos obtained of head and face injuries reported through the International Ski Federation Injury Surveillance System during 10 World Cup seasons (2006-2016). We analysed 57 head impact injury videos (alpine $n=29$, snowboard $n=13$, freestyle $n=15$ ), first independently and subsequently in a consensus meeting.

Results During the crash sequence, most athletes (84\%) impacted the snow with the skis or board first, followed by the upper or lower extremities, buttocks/pelvis, back and, finally, the head. Alpine skiers had sideways (45\%) and backwards pitching falls (35\%), with impacts to the rear (38\%) and side (35\%) of the helmet. Freestyle skiers and snowboarders had backwards pitching falls (snowboard $77 \%$, freestyle $53 \%$ ), mainly with impacts to the rear of the helmet (snowboard 69\%, freestyle 40\%). There were three helmet ejections among alpine skiers (10\% of cases), and $41 \%$ of alpine skiing injuries occurred due to inappropriate gate contact prior to falling. Athletes had one (47\%) or two (28\%) head impacts, and the first impact was the most severe $(71 \%)$. Head impacts were mainly on snow $(83 \%)$ on a downward slope (63\%).

Conclusion This study has identified several characteristics of the mechanisms of head injuries, which may be addressed to reduce risk.

\section{INTRODUCTION}

Head injuries represent a concern in alpine skiing, freestyle skiing and snowboarding. ${ }^{1-7}$ Traumatic brain injuries (TBIs) are the leading cause of death in recreational skiers and snowboarders, and are linked to acrobatic and high-speed activities. $^{2} 8$ During the Vancouver 2010 Olympic Winter Games (OWG), the head and cervical spine were the most common injury locations for both men and women. ${ }^{9}$ At the International Ski Federation (FIS) World Cup (WC) level, head and face injuries account for $10 \%$ to $13 \%$ of injuries that require medical attention in snowboarding, freestyle and alpine skiing ${ }^{4610} ; 82 \%$ were concussions, and $24 \%$ of these led to an absence from training or competition for $>28$ days. ${ }^{10}$ Since helmets are mandatory during official training, course inspection and competitions in all FIS WC events, these injury data cover a period where all athletes have been helmeted. ${ }^{11}$
A description of the inciting event, including a detailed characterisation of the head impact itself, is critical to understand the interaction of causative factors for head injuries among skiers and snowboarders. ${ }^{12}$ Previous studies have described the injury mechanisms at the recreational level based on surveys and hospital data, ${ }^{13-15}$ reconstructed specific head impact situations with anthropomorphic test devices or with computer modelling ${ }^{16-18}$ or used helmet-mounted accelerometers to measure head impact forces. ${ }^{19}$

A more detailed and reliable analysis of the head injury mechanisms can be obtained using systematic analyses of video from real injury situations, compared with relying on descriptions of the injury mechanisms from, for example, the athlete, coach, accident reports or interview data. ${ }^{20-22}$ Previously, the head impact kinematics of crashes have been described for a few cases. Yamazaki et al reconstructed one real case of a severe TBI in WC downhill skiing using a model-based image matching technique to describe the head impact kinematics. ${ }^{23}$ In addition, the head impacts of four injury cases in WC snowboarders and freestyle skiers ${ }^{24}$ and seven WC alpine skiers ${ }^{25}$ have recently been reconstructed to describe the head impact kinematics.

However, no systematic video analysis of the mechanisms for head injury in WC snowboarders, alpine and freestyle skiers has been performed. Therefore, the aim of this study was to analyse head and face injuries recorded by the FIS Injury Surveillance System (ISS) through 10 seasons (2006-2016) of WC alpine and freestyle skiing and snowboarding to describe their mechanisms.

\section{METHODS}

\section{Injury cases}

All head/face injuries reported through the FIS ISS from WC and OWG alpine, freestyle and snowboard competitions during the period 2006-2016 were identified for video analysis. ${ }^{14671026}$ Of the 123 injury cases, we obtained 57 injuries on video with the possibility of analysing the gross head injury mechanism (figure 1). We collected video recordings systematically from the WC television producer (Infront Media, $n=53$ ) and the IOC Multimedia Library $(n=4)$ at the end of each WC season (2006-2016).

An injury is defined through the FIS ISS as "all injuries that occurred during training or competition and required attention by medical personnel". ${ }^{27}$ The classification of 'head and face injuries' does not include the neck or cervical spine. Injury severity is defined according to the duration 


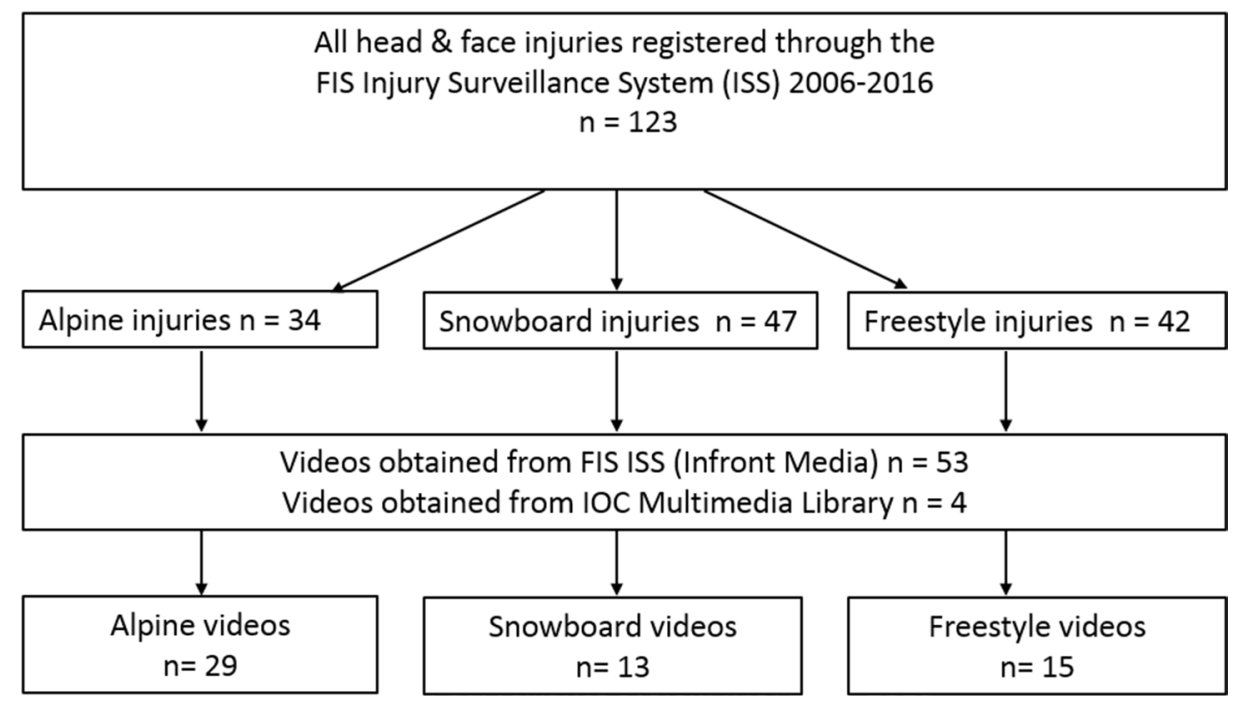

Figure 1 Flow chart of video acquisition process. FIS, International Ski Federation.

of absence from training and competition as slight (no absence), minimal (1-3 days), mild (4-7 days), moderate (8-28 days) and severe ( $>28$ days) ${ }^{28}$ The absence reported was attributed to the injury in question only. The definition of injury as well as the classification of injury type, body part injured and injury severity is based on a generalised definition and classification system used in injury surveillance, and not for head injuries, in particular. ${ }^{27}$

\section{Video processing}

All videos were converted to mp4 file format with H.264 encoding using Adobe Premiere Pro V.CS6 (Adobe Systems, San Jose, California, USA) and viewed using the frame-by-frame function in QuickTime V.7.7.9 (Apple, Cupertino, California, USA). The videos had frame rates of $25 \mathrm{~Hz}, 50 \mathrm{~Hz}$ and $60 \mathrm{~Hz}$ and the display aspect ratios were $4: 3$ or $16: 9$.

\section{Video analysis form}

We developed a specific analysis form for head/face injuries based on previous analysis forms used for analysis of injuries in alpine skiing and snowboard cross. ${ }^{29-31}$ The analysis form included closed questions regarding (1) the skiing/riding situation and gross body biomechanics preinjury, (2) analysis of the head impact in detail and (3) postinjury security net contact. In addition, there was one open question where analysts were asked to describe the head injury mechanism in their own words (video analysis form-online supplementary appendix 1).

\section{Video analysis}

Five expert analysts in the fields of sports medicine (RB, AB, $\mathrm{TB}, \mathrm{SES}$ ) or head injury biomechanics (DAP) formed the analysis team. Initially, injury videos for each case were analysed independently using the form. During this phase, all analysts were blinded to the opinions of others, but were provided with injury information on each case (sex, discipline and specific diagnosis). The primary investigator then summarised the analysis forms from all five analysts. Consensus was said to have been reached if at least three analysts selected the same response. Cases for which consensus was not reached were discussed during a meeting attended by all experts. During the meeting, injury videos were reviewed as many times as required to obtain agreement.

\section{Definition of main head impact injury frame}

The five analysts used the frame-by-frame function of the video player to independently evaluate how many head impacts were visible in each case and to decide which head impact they classified as the main head impact. Consensus was reached during the group meeting regarding the main head impact in each case, which was used for the impact frame analyses.

All 57 videos were analysed with respect to the inciting event (injury mechanism), as it was possible to see the preimpact skiing/riding situation. However, in eight cases, we did not have a clear view of the number of head impacts, and in nine cases the impact location on the helmet was not visible.

\section{Statistics}

We performed a Mann-Whitney U test to assess whether there was any difference in injury severity between the head/face injury cases analysed and the cases where we could not obtain videos. To investigate the association between the number of head impacts and injury severity, a [[[NO ENTITY $]]^{2}$ test was performed, assuming linear by linear association. To achieve sufficient statistical power, we regrouped the number of head impacts into the following categories: one impact, two impacts, three or more impacts, excluding cases where the number of impacts could not be assessed. For both statistical tests, a two-sided alpha level of $\leq 0.05$ was considered statistically significant. We used IBM SPSS Statistics V.24 (Armonk, New York, USA) for the analyses.

\section{RESULTS}

\section{Injury cases}

In alpine skiing, most of the cases were from the speed disciplines downhill $(n=14)$ and super- $G(n=11)$, followed by the technical disciplines giant slalom $(n=2)$ and slalom $(n=2)$. In snowboarding, the injuries occurred in snowboard cross $(n=12)$ and slopestyle $(n=1)$, whereas in freestyle skiing, the injuries occurred in ski cross $(n=10)$, aerials $(n=3)$, halfpipe $(n=1)$ and slopestyle $(n=1)$. There were 32 male $(56 \%)$ and 25 female $(44 \%)$ injured athletes. The age (mean \pm SD) of the athletes at the time of injury for alpine skiers, freestyle skiers and snowboarders was $27.0 \pm 5.7,22.1 \pm 3.0$ and $23.7 \pm 2.9$, respectively. The most common diagnoses, across all disciplines, were concussions $(n=39,68 \%)$, followed by head/face fractures $(n=6,11 \%)$ and 
Table 1 Consensus decision on the number of visible head impacts and classification of the main head impact

\begin{tabular}{|c|c|c|c|c|c|c|}
\hline \multicolumn{4}{|c|}{ No of head impacts } & \multicolumn{3}{|c|}{$\begin{array}{l}\text { Classification of main head } \\
\text { impact }\end{array}$} \\
\hline $\begin{array}{l}\text { Head } \\
\text { impacts }\end{array}$ & $\begin{array}{l}\text { Alpine } \\
\text { (n) }\end{array}$ & $\begin{array}{l}\text { Snowboard } \\
\text { (n) }\end{array}$ & $\begin{array}{l}\text { Freestyle } \\
\text { (n) }\end{array}$ & $\begin{array}{l}\text { Alpine } \\
\text { (n) }\end{array}$ & $\begin{array}{l}\text { Snowboard } \\
\text { (n) }\end{array}$ & $\begin{array}{l}\text { Freestyle } \\
\text { (n) }\end{array}$ \\
\hline 1 & 11 & 7 & 9 & 22 & 8 & 11 \\
\hline 2 & 10 & 3 & 3 & 5 & 2 & 1 \\
\hline 3 & 3 & 0 & 0 & 0 & 0 & 0 \\
\hline 4 & 2 & 0 & 0 & 0 & 0 & 0 \\
\hline 5 & 1 & 0 & 0 & 0 & 0 & 0 \\
\hline $\begin{array}{l}\text { Not } \\
\text { visible }\end{array}$ & 2 & 3 & 3 & 2 & 3 & 3 \\
\hline Total (n) & 29 & 13 & 15 & 29 & 13 & 15 \\
\hline
\end{tabular}

contusions $(n=6,11 \%)$. The injuries were classified as severe in 14 cases (25\%), moderate in $15(26 \%)$ and mild in 12 cases (21\%) (disciplines and medical information- online supplementary appendix 2). There was no significant $(\mathrm{P}=0.065)$ difference in injury severity between the head/face injury cases analysed $(n=57)$ and the injury cases where we could not obtain videos $(n=66)$.

\section{Analysis of the main head impact}

Most injury cases had one $(n=27,47 \%)$ or two $(n=16,28 \%)$ visible head impacts, and the first head impact was considered to be the main head impact in the majority of cases $(n=41,71 \%)$ (table 1). Among alpine skiers, 21\% $(n=6)$ of athletes experienced more than two head impacts. We could not assess the
Table 2 Impact location on the helmet $(n=57)$

\begin{tabular}{lllllll}
\hline & \multicolumn{2}{l}{ Impact location } & & \\
\cline { 2 - 5 } Discipline & Face/front & Top & Side & Back & Not visible \\
\hline Alpine & 3 & 2 & 10 & 11 & 3 \\
Snowboard & 2 & 0 & 0 & 9 & 2 \\
Freestyle & 4 & 0 & 1 & 6 & 4 \\
Total $(\mathrm{n})$ & 9 & 2 & 11 & 26 & 9 \\
\hline
\end{tabular}

number of head impacts in eight cases (14\%). There was no association between the number of head impacts and injury severity $(\mathrm{P}=0.260)$.

The most common impact location was the back of the helmet (46\%), followed by the side (19\%), the face or frontal part of the helmet (16\%) and the top (4\%) (table 2).

Most helmet impacts were on snow $(n=47,83 \%)$ and on a downward slope $(n=36,63 \%)$ (figure 2). In more than half of the cases, the helmet slid along the surface postimpact $(n=29$, 51\%). In three alpine skiing cases, the helmet ejected during the head impact. No helmet ejections in the snowboard or freestyle cases were observed.

Postimpact, 17 athletes (15 in alpine skiing and two in freestyle skiing) were in contact with the security net, which functioned adequately in 16 (94\%) of the cases. In one alpine skiing case, the security net did not function satisfactorily.

\section{GROSS HEAD INJURY MECHANISMS}

\section{Alpine}

Prior to the head impact situation, the majority of alpine skiers were turning $(n=16,55 \%)$ or landing after a jump $(n=9,31 \%)$.
Slope in relation to helmet at frame of impact $(n=57)$

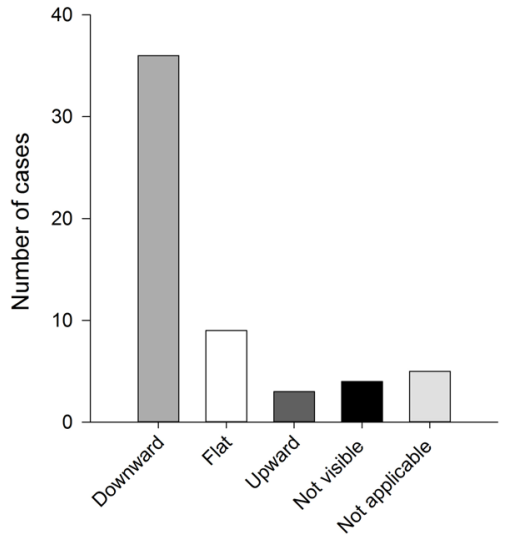

Helmet slides along surface post impact $(n=57)$

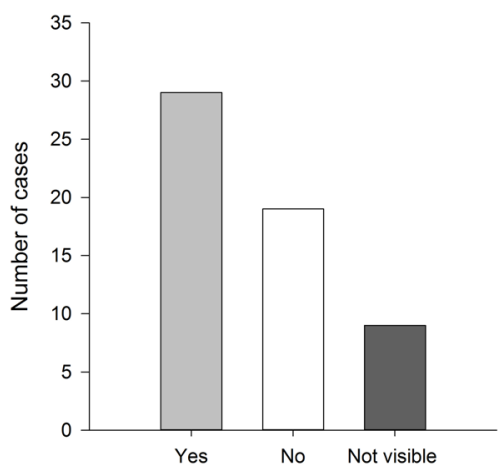

Surface of impact $(n=57)$

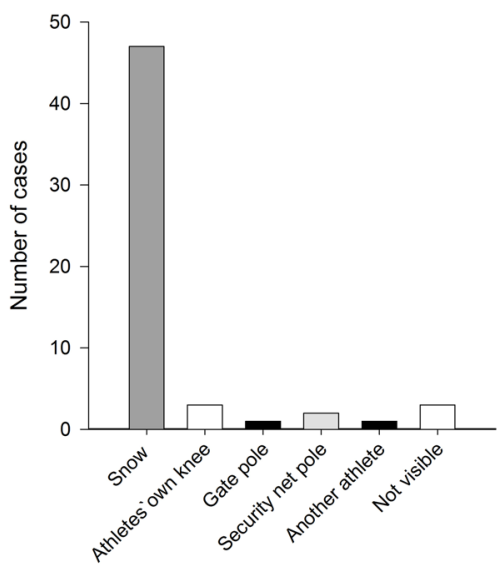

Helmet ejects $(n=57)$

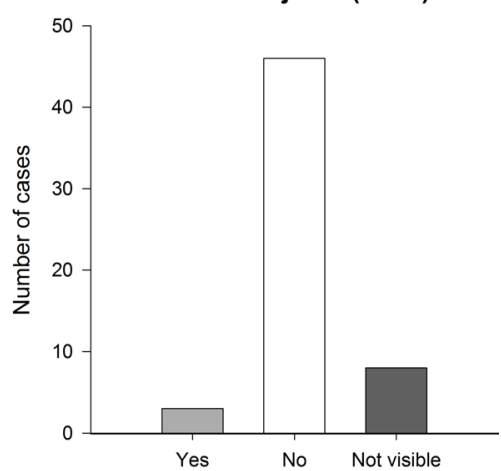

Figure 2 Analysis of the head impact frame (all disciplines, $\mathrm{n}=57$ ). 


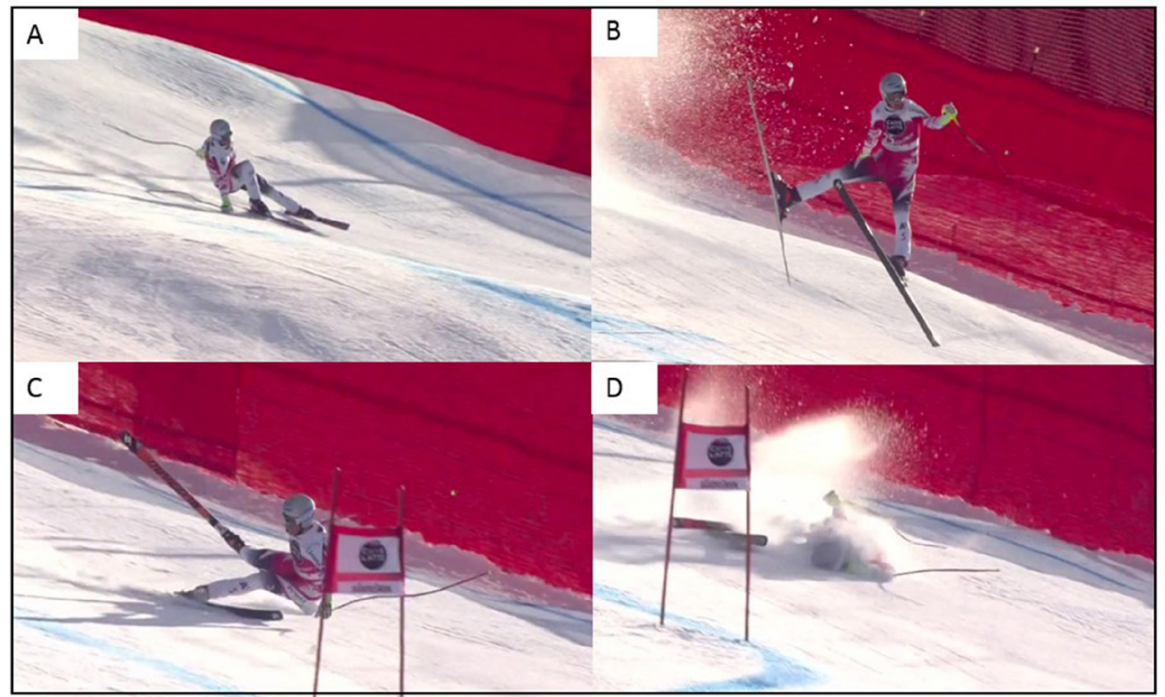

Figure 3 Alpine skier, typical example of a sideways fall. Key crash events: (A) The athlete is out of balance inwards and backwards after a jump. He loses pressure on the outer ski, which then catches the snow. (B-C) He hits a new bump, becomes airborne and yaws to the right, rolls to the left and pitches backwards. (D) The athlete lands on his left side and impacts the left side of the helmet (impact frame).

In all cases $(n=29)$, the athlete made a personal technical or tactical mistake, leading to an out-of-balance situation. In 12 cases $(41 \%)$, the athlete had inappropriate gate contact prior to crashing, causing the injury situation.

While still skiing prior to falling/crashing, they were out of balance in the frontal plane (roll), $\mathrm{n}=23,79 \%$, out of balance backward (rearward pitch), $n=13,45 \%$, or forward (forward pitch), $n=5,17 \%$, and/or out of balance in the transverse plane (yaw), $n=12,41 \%$. In all alpine skiing cases, the crash sequence was characterised by the skis having initial contact with the landing surface, that is, the snow, followed by the lower and upper extremities, the buttocks/pelvis, back and trunk/chest, with the head being the last to impact the snow surface (see example in figure 3).

The gross body movement during the fall/crash, prior to head impact, was characterised by combinations of the athletes rolling $(n=22,76 \%)$, yawing $(n=17,59 \%)$ and/or pitching $(n=15$, $52 \%)$. The body rotation during the fall/crash was classified as moderate $\left(90-180^{\circ}\right.$ in any direction) in 12 cases (41\%), minor $\left(<90^{\circ}\right)$ in 11 cases $(38 \%)$ or substantial $\left(>180^{\circ}\right)$ in 6 cases before head impact. The most common mechanisms of falling were sideways $(n=13,45 \%)$ or backward falls $(n=10,35 \%)$, followed by forward falls $(n=4,14 \%)$ or collisions $(n=2,7 \%)$ (figure 3 ).

\section{Snowboard}

Prior to the head impact situation, the snowboarders were landing after a jump $(n=5,39 \%)$, bank turning $(n=2,15 \%)$, in between elements $(n=2,15 \%)$ or had already crashed/fallen $(n=3,23 \%)$. A personal technical or tactical mistake contributed to the injury situation in eight $(62 \%)$ cases. One athlete had inappropriate gate contact, which was the cause of injury. In five (39\%) snowboard cross cases, the athlete made a forced error caused by contact with an opponent.

In 10 snowboarding cases where it was possible to analyse the crash sequence in detail, the crash sequence was characterised by the snowboard being in first contact with the snow, followed by the upper extremities, buttocks/pelvis, back, trunk/chest and lastly the head (figure 4).

All snowboarders were out of balance in the transverse plane (yawing) prior to falling/crashing $(\mathrm{n}=13,100 \%)$, and most of the riders were also out of balance backwards (rearward pitch, $n=12,92 \%)$. Over half $(n=8,62 \%)$ of the snowboarders caught the back edge of the snowboard prior to head impact (see example in figure 4). The gross body movement during the fall/crash, prior to head impact, was characterised by combinations of the athletes pitching $(n=13,100 \%)$, yawing $(n=8,62 \%)$ and/or rolling $(n=3,23 \%)$, with minor $(n=6,46 \%)$, moderate $(n=4,31 \%)$ or substantial $(n=3,23 \%)$ body rotation. Snowboarders primarily fell backwards $(n=10,77 \%)$; however, two fell forwards (15\%) and one collided with another athlete (8\%).

\section{Freestyle}

Prior to the head impact situation, the majority of freestyle skiers were landing after a jump $(n=10,67 \%)$. The athletes fell or crashed in almost all cases $(n=13,87 \%)$. In two aerials cases, the freestyle athletes did not fall or crash; however, the athlete's face impacted their own knee during a forward pitch during landing. The majority of freestyle athletes $(n=13,87 \%)$ made a personal technical or tactical mistake prior to crashing. In two ski cross cases $(13 \%)$, the athletes made a forced error caused by opponent contact.

It was possible to analyse the crash sequence in detail in nine freestyle cases. During the crash sequence, the skis were in first contact with the landing surface, followed by the upper extremities, buttocks/pelvis, back and trunk/chest, and the head was the last body part to impact the snow (see examples in figures 5 and 6).

Freestyle skiers were out of balance backwards (rearward pitch, $\mathrm{n}=8,53 \%)$, rolling $(\mathrm{n}=5,33 \%)$ and/or yawing $(\mathrm{n}=4$, $27 \%$ ) prior to crashing. The gross body movement during the fall/crash, prior to head impact, was characterised by the athletes pitching $(n=9,60 \%)$, yawing $(n=6,40 \%)$ and/or rolling $(n=5,33 \%)$, with minor $(n=6,40 \%)$, moderate $(n=4$, $27 \%)$ or substantial $(n=2,13 \%)$ body rotation. In three cases, the athletes had no visible body rotation precrash. Freestyle skiers primarily fell backwards $(n=8,53 \%)$, sideways $(n=3$, $20 \%)$, forwards $(n=1,7 \%)$ or did not fall/crash $(n=2,13 \%)$ (figures 5 and 6). In one freestyle case, the crash situation was not visible. 


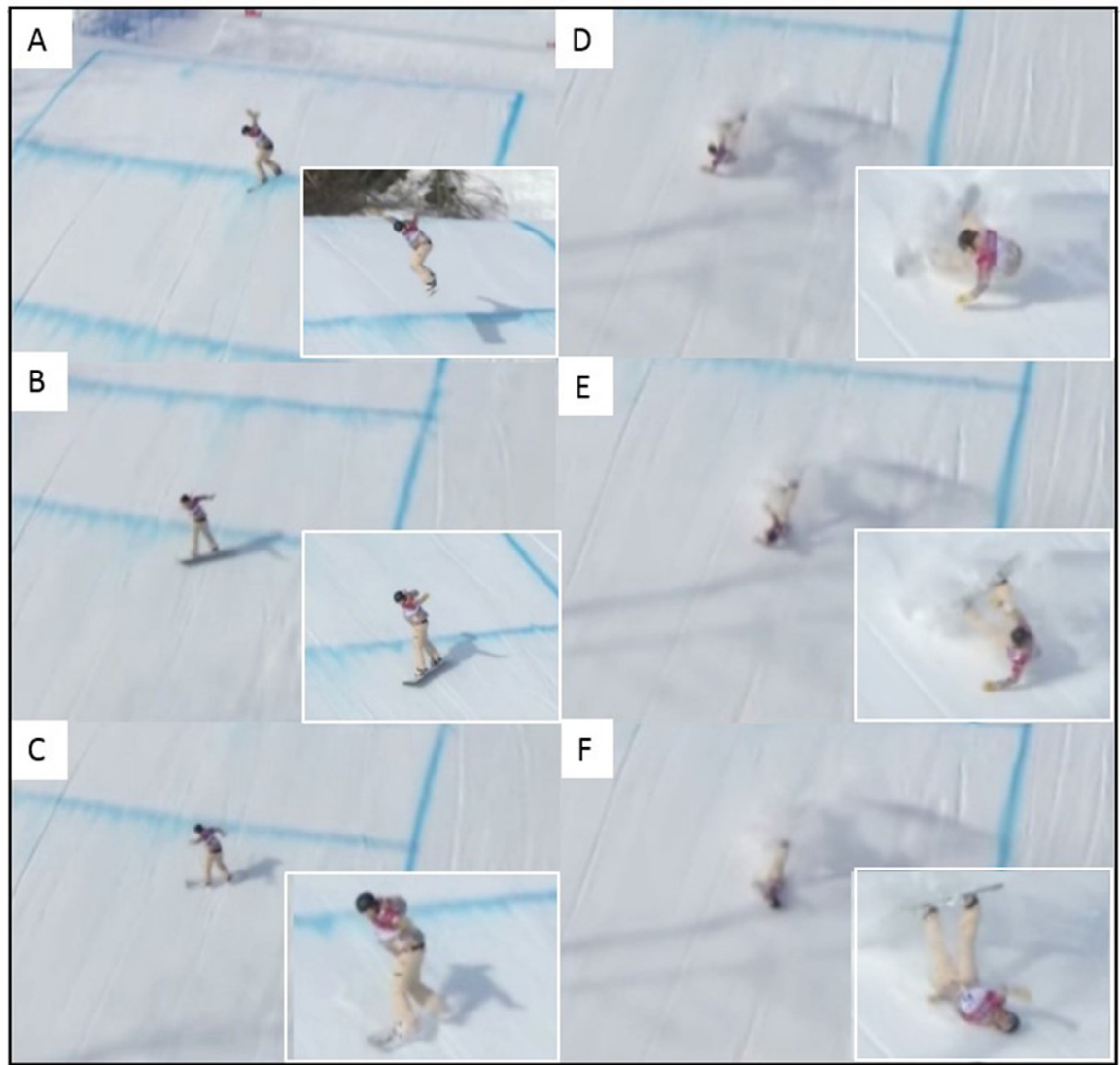

Figure 4 Snowboard cross, typical example of a back-edge catch. Key crash events: (A) The athlete is out of balance backwards and yawing during landing after a jump. (B) She continues to yaw on landing. Her bodyweight is first on the frontside edge of her snowboard. (C) Her bodyweight shifts to the backside edge. The back edge catches the snow surface. (D) She pitches backwards and impacts her buttocks, (E) followed by her upper extremity and back, (F) and then impacts the back of her helmet (impact frame).

\section{DISCUSSION}

The present study is the first to systematically analyse the mechanisms for head injuries in detail, including a substantial number of cases from elite alpine and freestyle skiing and snowboarding. Across all disciplines, most falls were backwards pitching and sideways falls, and we observed a common landing sequence during the crash situation: the athletes impacted the snow surface with their skis or board first, followed by the upper or lower extremities, buttocks/pelvis, back and, finally, the head. As a result of this crash sequence, impacts to the rear and side of the helmet dominated. It should also be noted that among alpine skiers, a high proportion of injuries resulted from inappropriate gate contact, and we observed three helmet ejections, which represents a concern.

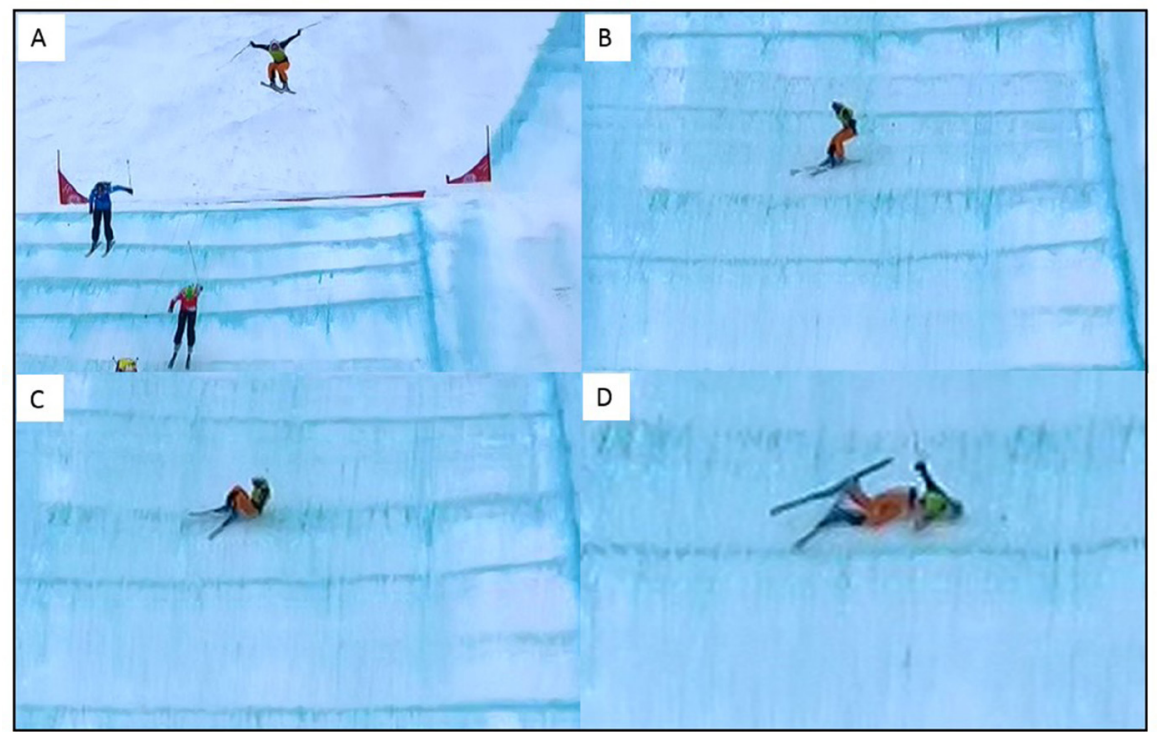

Figure 5 Freestyle ski cross, typical example of a backwards pitching fall. Key crash events: (A) Inappropriate course line and damping of jump. The athlete is out of balance backwards and yawing during the flight phase. (B) The athlete lands on skis with skis partially across the slope. (C) The athlete pitches backwards, impacting her buttocks. (D) Rolls to the side and impacts the side of the helmet (impact frame). 


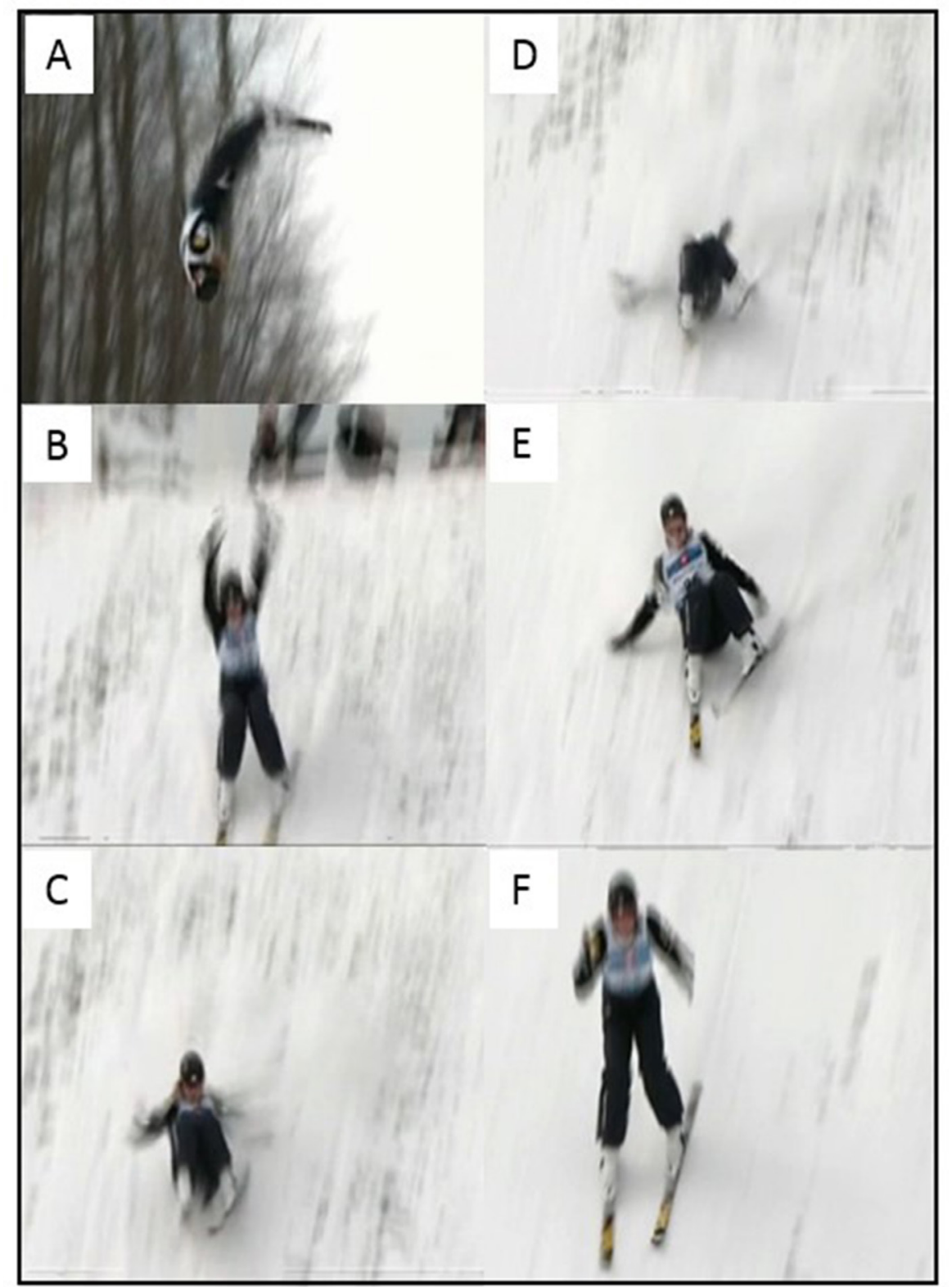

Figure 6 Freestyle aerials, example of a 'slapback' head impact. Key crash events: (A) The athlete is airborne during an inverted jump. (B) The athlete has over-rotated the jump and lands back-weighted. (C) Continues to rotate and pitches backward. (D) The back of the helmet impacts the snow (impact frame). (E) The head and upper body rebound up from the snow. (F) The athlete stands up fully.

\section{Common crash sequence across disciplines}

The athletes impacted the snow surface with their skis or board first, followed by the upper or lower extremities, buttocks/pelvis, back and, finally, the head $(n=48,84 \%)$. This information is important to increase the ecological validity of future head impact injury reconstructions. For example, a previous laboratory reconstruction of snowboarding back edge catches with anthropomorphic test devices presented them as being flipped up in the air after the edge catch, with the hips and spine in full extension and landing directly onto the head. ${ }^{17}$ This is not a realistic reconstruction of a snowboarding back-edge catch event, based on our findings (see figure 4). The identification of this crash sequence may also be important for further development of wearable ski-racing airbags, specifically in relation to airbag deployment, that is, the triggering algorithm. Airbags were first used in official FIS WC races in the 2015/2016 season. However, further design improvements may be possible, particularly with respect to protecting the cervical spine and head in backward pitching falls, as described in the current paper.

\section{Sideways falls common in alpine skiing}

Among alpine skiers, sideways falls were common (45\%). Two common patterns were observed. The athletes were either mainly out of balance in the frontal plane (roll) in air during flight, falling to the left or right hand side, impacting the side of the helmet, or the athletes landed mainly out of balance in the transverse plane (yaw) after flight, subsequently catching the ski edge and tripping. Being tripped, the athlete then fell sideways, also impacting the side of the helmet (figure 3).

Our findings are slightly contradictory to a recent study investigating head injury mechanisms in recreational skiers and snowboarders, where hospital data were combined with a survey based on sketches depicting the crash and impact locations. ${ }^{13}$ Bailly et 
al reported that 'Falling head first' while skiing was the most common injury mechanism (28\%), followed by 'Falling sideways (catching the ski edge)' representing 19\% of skiers' falls. ${ }^{13}$ The two main head impact locations were the frontal $(57 \%)$ and facial $(41 \%)$ areas. ${ }^{13}$ However, for the sideways falls, they reported that $28 \%$ of head impacts were to the occipital region, which is similar to our findings. ${ }^{13}$ This indicates that mechanisms of falling may be somewhat different between recreational and WC skiers, with recreational skiers having more impacts to the front/face and falling head first, although catching the ski edge and falling sideways has been identified as a common injury mechanism at both levels.

\section{Backwards pitching falls common in freestyle and snowboard} Backwards pitching falls were the most common among snowboarders and freestyle skiers in our study. We observed two previously described types of backward pitching falls among our freestyle and snowboarding cases: 'slapback' injuries and back-edge catches. ${ }^{19} 32$ The gross injury mechanism in 62\% of our snowboarding cases was a 'back-edge catch' (opposite edge catch), which is previously described as a common head injury mechanism in snowboarders. ${ }^{32} 33$

Backward pitching falls were frequently observed in alpine skiing as well (35\%). Bailly et al reported that falling backwards represented $14 \%$ of falls in recreational skiers, with the impact location being the occipital region in $73 \%$ of the backwards falls. ${ }^{13}$ Backwards pitching falls may therefore be more common among WC alpine skiers compared with in recreational skiers.

\section{Helmet ejections in alpine skiing: cause for concern}

Among the alpine skiing cases, there were three helmet ejections at head impact (10\% of cases). From the visual analysis, the cause of the helmet ejections cannot be determined. It could be that the helmet did not fit adequately, was not securely fastened or that the loads of the crash exceeded the stability of the helmet/ strap.

One of the main requirements of a helmet is to provide and maintain appropriate and adequate coverage to the head, and a helmet that is poorly fitted or fastened may become displaced during normal use or even ejected during a crash. ${ }^{34}$ Among cyclists, a recent study investigated the fit of helmets and reported that bicycle helmets worn by recreational and commuter cyclists are often the wrong size and often worn and adjusted incorrectly. ${ }^{35}$ In addition, among motorcyclists, helmet type and wearing correctness were among the factors that affected the loads at which helmets became displaced. ${ }^{34}$ However, the athletes in the current study were supported by professional teams and therefore likely received optimal advice and optimally fitted helmets from their equipment suppliers. Therefore, the helmet ejections observed represent a concern.

\section{Many cases of inappropriate gate contact}

In the alpine skiing cases, over $40 \%$ of the athletes had inappropriate gate contact, which threw the skier out of balance and ultimately led to the crash. In most cases, the gate contact resulted from a personal mistake of the skier (misjudging the turn/skiing line or having an inappropriate course line) and therefore hooking the gate with the upper extremity, impacting the gate panel, or straddling the gate with the inner ski. This is supported by previous video analysis of WC alpine skiing injuries in general, where in $30 \%$ of cases inappropriate gate contact caused the injury situation. ${ }^{29}$ From the 2010/2011 season, FIS enforced the use of release gate panels, which must release from the pole when the athlete collides with the gate, ${ }^{11}$ yet further design improvements may be possible.

\section{Head impacts and impact location}

Although most athletes experienced one head impact, many athletes (28\%) experienced two, and in alpine skiing, some (21\%) even more than two impacts. Alpine ski helmets have been demonstrated to provide protection against low-severity repetitive impacts, such as impacting slalom gates. ${ }^{36}$ However, ski helmet liner materials exhibit degradation in performance for substantial repetitive impacts, ${ }^{37}$ which may be an important consideration for helmet manufacturers with respect to helmet design and construction, although we did not detect an association between the number of head impacts and injury severity. However, we do not know whether the helmets used had suffered previous impacts.

Few impacts were to the front of the helmet or the face (16\%); however, the face is mostly unprotected. In fact, we observed two cases in freestyle aerials where the athletes did not crash, but impacted their face onto their own knees, one suffering an orbital blow-out fracture. In contrast, at the recreational level, facial bone fractures and dental injuries are reported among male snowboarders and skiers to occur most frequently after falls or collisions with other persons. ${ }^{38} 39$

Head impact location, mainly to the back and side of the helmet, and impacting snow/ice (83\%), may be important information for helmet manufacturers, as at the recreational level collisions with stationary objects or other skiers/riders might be more common. ${ }^{40-43}$

\section{Helmets continue moving postimpact}

In half of the cases, the helmet slid along the surface postimpact. A variable to evaluate helmet rebound motion up from the snow surface postimpact was not included in the video analysis form. In previous reconstructions of skiing and snowboarding head impact injuries, both linear and angular velocity changes indicated that there was a rebound phase immediately postimpact, which might not be anticipated in an impact with a compliant surface such as snow. ${ }^{24}$ Although helmet rebound was not specifically investigated in this study, the helmet was observed to not stop moving postimpact in most cases.

\section{Methodological considerations and limitations}

The current study sample was derived from a systematic, prospective collection of injury videos over a 10 -year period (2006-2016) based on the FIS ISS. We managed to acquire videos of $85 \%$ (29/34) of all WC alpine head and face injuries, ensuring that our sample of alpine injury videos is representative. However, we could only obtain videos of $28 \%(13 / 47)$ and $36 \%(15 / 42)$ of snowboarding and freestyle skiing head and face injuries, respectively, for the same period. This was mainly due to injuries not being videotaped by the television producer or the injury situation was not visible on the video. In addition, many head and face injuries in snowboard and freestyle skiing occur during qualification runs, which are not broadcasted. Therefore, the data from freestyle skiing and snowboarding should be interpreted with caution. Nevertheless, our findings parallel previous epidemiological literature.

We did not detect any difference in injury severity between the cases with and without video available; this suggests that the sample we were able to analyse is representative.

The injury recording was through interviews with athletes, medical personnel or coaches. Recall bias is a challenge with 
retrospective interviews. However, a methodological study found that in the WC setting, retrospective interviews was the best method compared with prospective injury registration by team medical personnel or FIS Technical Delegates. ${ }^{28}$ Interview forms based on the race schedules were used to help the interviewee recall the date, location and circumstances of injury. ${ }^{28}$ However, a limitation is that we did not have access to more detailed medical information, for example, the results of imaging studies done or standard severity scores such as Glasgow Coma Scale or Abbreviated Injury Scale.

A greater problem could be that concussions are not recognised by athletes, coaches or medical personnel, and therefore are under-reported. Athletes might not self-report an injury they do not recognise as being harmful or dangerous at the time of competition. ${ }^{445}$ From other sports, it is known that concussions are under-reported to a large extent. ${ }^{46-49}$

Video quality and available camera views represent a challenge when determining the head impact frame and when assessing the gross injury mechanisms. It should be noted, however, that the assessment was consistent across analysts.

We included videos where the head impact frame was not visible. However, we could still perform an accurate analysis of the gross body biomechanics leading up to the head injury, which provides novel and valuable information.

\section{Further perspectives}

Based on the three helmet ejections we observed, it seems prudent to ensure that FIS WC athletes have optimally fitting helmets, which are fastened correctly, as this could potentially be an area of improvement with respect to athlete safety.

Our observation that the helmet continues moving postimpact, combined with findings from previous papers ${ }^{24} 25$ describing a linear and angular rebound motion up from the snow surface, could be an important consideration for helmet manufacturers. Both the helmet and the snow impact surface may contribute to rebound, and future helmet standards could potentially address these issues. ${ }^{2425}$

Based on information about real gross head injury mechanisms, future biomechanical studies could reconstruct realistic crash sequences, as this might help our understanding of the comparability of laboratory reconstructions or computer modelling and real head impact injuries on a snow surface.

FIS has developed gates with panels/poles offering less resistance or with an optimised release mechanism when hooking. This effort should continue based on the high number of inappropriate gate contacts that lead to head injuries (and knee injuries) ${ }^{29}$ in alpine skiing.

In snowboarding and freestyle skiing, most head injuries occurred during landing from a jump or when crashing while passing an element. The primary focus for course design should therefore be on safe jump and landing constructions, and on the design of elements, such as banked turns. Several previous studies using computer modelling techniques have investigated if the creation of safer terrain park jump designs that reduce the risk of impact injuries is possible. ${ }^{50-53}$ In particular, it has been discussed if the severity of impact risk can be characterised by equivalent fall height, a measure of jumper impact velocity normal to the slope. ${ }^{51}$ The thought is that the smaller the equivalent fall height, the smaller the probability of serious injury resulting from impacts normal to the snow surface. ${ }^{52}$ However, the crash sequence we described, with the skis/board having initial contact, followed by the extremities, buttocks, back and lastly the head, could mean that not only the normal-to-slope equivalent fall height could be of importance to the impact severity, but this pitching motion could possibly also contribute to the severity of head impact injury. We therefore reiterate the necessity of future biomechanical studies to reconstruct crash sequences realistically.

In alpine skiing, safe course design in general, and not only for jumps, must be a priority. Further investigations into the reasons athletes make mistakes during turning, and into the causes of inappropriate gate contact, are therefore warranted, in addition to addressing jump safety. Spörri et al reported that the main perceived risk factors among alpine expert stakeholders were system ski, binding, plate and boot; changing snow conditions; physical aspects of the athletes; speed and course setting aspects and speed in general. ${ }^{54}$ Gilgien et al reported that in fall or crash situations, the magnitude of speed is of particular importance since speed determines the kinetic energy that has to be dissipated during a crash impact. ${ }^{55}$ In technically demanding sections such as jumps, rough terrain and turns, anticipation and adaptation time decrease with speed and mistakes might be more likely to occur. ${ }^{55}$ Simulation models of jump landings in WC downhill skiers suggested that limited preparation time, high take-off speeds, steep take-off angles and landings in flat terrain had the most influence on landing impact injury risk. ${ }^{56}$ It therefore seems reasonable to suggest that reducing skier speeds especially during turns and terrain transitions, and focusing on optimal safety jump design would reduce injury risk.

\section{What are the findings?}

- This is the first study to use video analysis to systematically analyse a substantial number of head and face impact injury cases among International Ski Federation World Cup alpine and freestyle skiers and snowboarders.

- We identified a common landing sequence during the crash, where the athletes impacted the snow surface with the skis or board first, followed by the upper or lower extremities, buttocks/pelvis, back and, finally, the head.

- Gross head injury mechanisms were characterised mainly by backward pitching falls with impacts to the rear of the helmet in all disciplines, and also by sideways falls and impacts to the side of the helmet in alpine skiers.

- Many athletes experienced two or more head impacts, which may be an important consideration for helmet manufacturers with respect to helmet design and construction.

How might it impact on clinical practice in the future?

- Potential at-risk situations for head and face injuries have been identified, which might help inform athletes, coaches and event organisers.

- Knowledge about gross head and face injury mechanisms can provide valuable information for event organisers and course builders with respect to designing safer courses and jumps in the future.

- This study gives valuable information about gross head injury mechanisms for helmet manufacturers, for developers of other safety equipment such as wearable airbags, for designers of ski gate poles and panels, and for future studies aiming to reconstruct realistic head impact injury mechanisms among skiers and snowboarders. 


\section{CONCLUSION}

Head and face injuries among FIS WC alpine and freestyle skiers and snowboarders mostly occurred while turning or landing from a jump. Most falls were backwards pitching and sideways falls, with a common crash sequence of impacting the snow surface with the skis or board first, followed by the upper or lower extremities, buttocks/pelvis, back and finally the head. Impacts to the rear and side of the helmet dominated, and most athletes experienced one or two head impacts. In alpine skiing, the high number of injuries occurring due to inappropriate gate contact, and the proportion of helmet ejections observed represent a concern.

Acknowledgements We thank the World Cup athletes, coaches and medical team personnel who participated in this study, and the International Ski Federation staff and officials for practical support. We thank Professor Lars Engebretsen and Dr Torbjørn Soligard from the IOC for assistance in obtaining videos from the Olympic Winter Games.

Contributors All authors have made substantial contributions to all of the following: (1) the conception and design of the study, or acquisition of data, or analysis and interpretation of data; (2) drafting the article or revising it critically for important intellectual content; and (3) final approval of the version to be submitted.

Funding The Oslo Sports Trauma Research Center has been established at the Norwegian School of Sport Sciences through generous grants from the Royal Norwegian Ministry of Culture, the South-Eastern Norway Regional Health Authority, the International Olympic Committee, the Norwegian Olympic and Paralympic Committee and Confederation of Sport, and Norsk Tipping AS. The FIS Injury Surveillance System is supported by the International Ski Federation and was established through a generous grant from DJO.

Competing interests None declared.

Ethics approval The study was reviewed by the Regional Committee for Medical Research Ethics, South-Eastern Norway Regional Health Authority, Norway.

Provenance and peer review Not commissioned; externally peer reviewed.

(c) Article author(s) (or their employer(s) unless otherwise stated in the text of the article) 2018. All rights reserved. No commercial use is permitted unless otherwise expressly granted.

\section{REFERENCES}

1 Flørenes TW, Nordsletten L, Heir S, et al. Injuries among World Cup ski and snowboard athletes. Scand J Med Sci Sports 2012;22:58-66.

2 Hagel BE, Goulet C, Platt RW, et al. Injuries among skiers and snowboarders in Quebec. Epidemiology 2004;15:279-86.

3 Kim S, Endres NK, Johnson RJ, et al. Snowboarding injuries: trends over time and comparisons with alpine skiing injuries. Am J Sports Med 2012;40:770-6.

4 Bere T, Flørenes TW, Nordsletten L, et al. Sex differences in the risk of injury in World Cup alpine skiers: a 6-year cohort study. Br J Sports Med 2014;48:36-40.

5 Soligard T, Steffen K, Palmer-Green D, et al. Sports injuries and illnesses in the Sochi 2014 Olympic Winter Games. Br J Sports Med 2015;49:441-7.

6 Major DH, Steenstrup SE, Bere T, et al. Injury rate and injury pattern among elite World Cup snowboarders: a 6-year cohort study. Br J Sports Med 2014;48:18-22.

7 Flørenes TW, Heir S, Nordsletten L, et al. Injuries among World Cup freestyle skiers. Br J Sports Med 2010;44:803-8.

8 Ackery A, Hagel BE, Provvidenza C, et al. An international review of head and spinal cord injuries in alpine skiing and snowboarding. Inj Prev 2007;13:368-75.

9 Engebretsen L, Steffen K, Alonso JM, et al. Sports injuries and illnesses during the Winter Olympic Games 2010. Br J Sports Med 2010;44:772-80.

10 Steenstrup SE, Bere T, Bahr R. Head injuries among FIS World Cup alpine and freestyle skiers and snowboarders: a 7-year cohort study. Br J Sports Med 2014;48:41-5.

11 FIS. Specifications for competition equipment and commercial markings. 2016: International Ski Federation. http://www.fis-ski.com/mm/Document/documentlibrary/ Marketing/04/30/53/Competitionequipment_1617_11072016_clean_English.pdf (accessed 29 Nov 2016).

12 Bahr R, Krosshaug T. Understanding injury mechanisms: a key component of preventing injuries in sport. Br J Sports Med 2005;39:324-9.

13 Bailly $\mathrm{N}$, Afquir $\mathrm{S}$, Laporte JD, et al. Analysis of injury mechanisms in head injuries in skiers and snowboarders. Med Sci Sports Exerc 2017;49:1-10.

14 Fukuda O, Takaba M, Saito T, et al. Head injuries in snowboarders compared with head injuries in skiers. A prospective analysis of 1076 patients from 1994 to 1999 in Niigata, Japan. Am J Sports Med 2001;29:437-40.

15 Koyama S, Fukuda O, Hayashi N, et al. Differences in clinical characteristics of head injuries to snowboarders by skill level. Am J Sports Med 2011;39:2656-61.
16 Bailly N, Llari M, Donnadieu T, et al. Head impact in a snowboarding accident. Scand J Med Sci Sports 2017;27:964-74.

17 Richards D, Carhart M, Scher I, et al. Head kinematics during experimental snowboard falls: implications for snow helmet standards. J ASTM Int 2008:5:101406.

18 Scher I, Richards D, Carhart M. Head injury in snowboarding: evaluating the protective role of helmets. J ASTM Int 2006;3:14203.

19 Mecham MD, Greenwald RM, Macintyre JG, et al. Incidence and severity of head impact during freestyle aerial ski jumping. J App/ Biomech 1999;15:27-35.

20 Krosshaug T, Andersen TE, Olsen OE, et al. Research approaches to describe the mechanisms of injuries in sport: limitations and possibilities. Br J Sports Med 2005;39:330-9.

21 Caswell SV, Lincoln AE, Almquist JL, et al. Video incident analysis of head injuries in high school girls' lacrosse. Am J Sports Med 2012;40:756-62.

22 Lincoln AE, Caswell SV, Almquist JL, et al. Video incident analysis of concussions in boys' high school lacrosse. Am J Sports Med 2013;41:756-61.

23 Yamazaki J, Gilgien M, Kleiven $S$, et al. Analysis of a severe head injury in World Cup alpine skiing. Med Sci Sports Exerc 2015;47:1113-8.

24 Steenstrup SE, Mok KM, McIntosh AS, et al. Head impact velocities in FIS World Cup snowboarders and freestyle skiers: do real-life impacts exceed helmet testing standards? Br J Sports Med 2017:bjsports-2016-097086 (Epub ahead of print 10 Jul 2017).

25 Steenstrup SE, Mok K-M, McIntosh AS, et al. Head impact reconstruction in FIS World Cup alpine skiers. Br J Sports Med- in press 2017.

26 Flørenes TW, Bere T, Nordsletten L, et al. Injuries among male and female World Cup alpine skiers. Br J Sports Med 2009;43:973-8.

27 Fuller CW, Ekstrand J, Junge A, et al. Consensus statement on injury definitions and data collection procedures in studies of football (soccer) injuries. Br J Sports Med 2006;40:193-201.

28 Flørenes TW, Nordsletten L, Heir S, et al. Recording injuries among World Cup skiers and snowboarders: a methodological study. Scand J Med Sci Sports 2011;21:196-205

29 Bere T, Flørenes TW, Krosshaug T, et al. A systematic video analysis of 69 injury cases in World Cup alpine skiing. Scand J Med Sci Sports 2014;24:667-77.

30 Bere T, Flørenes TW, Krosshaug T, et al. Mechanisms of anterior cruciate ligament injury in World Cup alpine skiing: a systematic video analysis of 20 cases. Am J Sports Med 2011;39:1421-9.

31 Bakken A, Bere T, Bahr R, et al. Mechanisms of injuries in World Cup snowboard cross: a systematic video analysis of 19 cases. Br J Sports Med 2011;45:1315-22.

32 Nakaguchi $H$, Tsutsumi K. Mechanisms of snowboarding-related severe head injury: shear strain induced by the opposite-edge phenomenon. J Neurosurg 2002;97:542-8

33 Nakaguchi H, Fujimaki T, Ueki K, et al. Snowboard head injury: prospective study in Chino, Nagano, for two seasons from 1995 to 1997. J Trauma 1999:46:1066-9.

34 Thai KT, McIntosh AS, Pang TY. Factors affecting motorcycle helmet use: size selection, stability, and position. Traffic Inj Prev 2015;16:276-82.

35 Thai KT, McIntosh AS, Pang TY. Bicycle helmet size, adjustment, and stability. Traffic Inj Prev 2015;16:268-75.

36 Swarén $\mathrm{M}$, Holmberg H-C, Eriksson A. Repeated low impacts in alpine ski helmets. Sports Technology 2013;6:43-52.

37 Stewart $D$, Young $L R$, Goel $R$, et al. Evaluating the performance of helmet linings incorporating fluid channels. J ASTM Int 2010;7:102821.

38 Tuli T, Haechl O, Berger N, et al. Facial trauma: how dangerous are skiing and snowboarding? J Oral Maxillofac Surg 2010;68:293-9.

39 Gassner R, Vàsquez Garcia J, Leja W, et al. Traumatic dental injuries and Alpine skiing. Endod Dent Traumatol 2000;16:122-7.

40 Levy AS, Hawkes AP, Hemminger LM, et al. An analysis of head injuries among skiers and snowboarders. J Trauma 2002;53:695-704.

41 Siu TL, Chandran KN, Newcombe RL, et al. Snow sports related head and spinal injuries: an eight-year survey from the neurotrauma centre for the Snowy Mountains, Australia. J Clin Neurosci 2004;11:236-42.

42 Greve MW, Young DJ, Goss AL, et al. Skiing and snowboarding head injuries in 2 areas of the United States. Wilderness Environ Med 2009;20:234-8.

43 Ruedl G, Bilek H, Ebner H, et al. Fatalities on Austrian ski slopes during a 5-year period. Wilderness Environ Med 2011;22:326-8.

44 Greenwald RM, Chu JJ, Beckwith JG, et al. A proposed method to reduce underreporting of brain injury in sports. Clin J Sport Med 2012;22:83-5.

45 Davies SC, Bird BM. Motivations for underreporting suspected concussion in college athletics. J Clin Sport Psychol 2015;9:101-15.

46 Williamson IJ, Goodman D. Converging evidence for the under-reporting of concussions in youth ice hockey. Br J Sports Med 2006:40:128-32.

47 McCrea M, Hammeke T, Olsen G, et al. Unreported concussion in high school football players: implications for prevention. Clin J Sport Med 2004;14:13-17.

48 Register-Mihalik JK, Guskiewicz KM, McLeod TC, et al. Knowledge, attitude, and concussion-reporting behaviors among high school athletes: a preliminary study. J Athl Train 2013;48:645-53.

49 Meier TB, Brummel BJ, Singh R, et al. The underreporting of self-reported symptoms following sports-related concussion. J Sci Med Sport 2015; 18:507-11 


\section{Original article}

50 McNeil JA, Hubbard M, Swedberg AD. Designing tomorrow's snow park jump. Sports Engineering 2012;15:1-20.

51 Hubbard M, Swedberg AD. Design of Terrain Park Jump Landing Surfaces for Constant Equivalent Fall Height Is Robust to "Uncontrollable" Factors. Skiing Trauma and Safety 19, 2012.

52 Hubbard M. Safer Ski jump landing surface design limits normal impact velocity. Journal of ASTM International. 6:1, 2009.

53 McNeil JA, McNeil JB. Dynamical analysis of winter terrain park jumps. Sports Engineering 2009;11:159-64.
54 Spörri J, Kröll J, Amesberger G, et al. Perceived key injury risk factors in World Cup alpine ski racing —an explorative qualitative study with expert stakeholders. $\mathrm{Br} J$ Sports Med 2012;46:1059-64.

55 Gilgien M, Spörri J, Kröll J, et al. Mechanics of turning and jumping and skier speed are associated with injury risk in men's World Cup alpine skiing: a comparison between the competition disciplines. Br J Sports Med 2014;48:742-7.

56 Schindelwig K, Reichl W, Kaps P, et al. Safety assessment of jumps in ski racing. Scand J Med Sci Sports 2015;25:797-805. 